\title{
Efek Demokrasi Dalam Pemilihan Langsung Calon Gubernur atau Bupati
}

\author{
Mulyadi J. Amalik
}

The election of local poitical leader (governor or resident) has lead to the rise of various conflicts among grassroots society. Not only because of the different political affiliation of people extremely vary, but also. Intervention from central government and central political party which distract the democratic process, but also feudalistic argumentation quite often raises in this process. In Yogyakarta as a case in point. The controversy raises due to the unclear definition of the distinction and particularity of Yogyakarta, in which Sultan traditionally is regarded as the most powerful man deserves to be leader and Pakualam as the vice of governor. This kind of conflicting cases will be analyzed in this article.

$\mathrm{B}$ anyak pihak yang khawatir dengan pemilihan langsung terhadap calon presiden, gubernur, atau bupati. Kekhawatiran itu terkait dengan dua hal yang serius, yaitu pertama, terjadinya konflik terbuka antarpemilih yang berbeda sehingga menimbulkan peluang kekacauan atau kerusuhan sosial; dan kedua, terjadinya money politics besar-besar yang kelak mengakibatkan irasionalitas dalam budaya politik Indonesia. Bagi calon presiden, gubernur, atau bupati dari partai politik yang berkuasa atau calon dari partai politik yang berada di pemerintahan dikhawatirkan pula akan melakukan penyalahgunaan wewenang dan kekuasaannya. Dalam wacana budaya politik modern semua kekhawatiran itu terkait dengan masalah yang saat ini sedang mewabah di Indonesia, yaitu korupsi, selain kolusi dan nepotisme.

Akan tetapi, bagi kelompok yang tidak khawatir pada pemilihan langsung calon presiden, gubernur, atau bupati, semua mekanisme itu dianggap sebagai investasi besar ke arah demokratisasi politik dan budaya politik yang rasional. Oleh karena itu, akibat-akibat buruk yang dikhawatirkan oleh kelompok yang cemas di atas justru dapat dijadikan pelajaran yang sangat berharga untuk menggagas pemilihan langsung khusus bagi calon gubernur atau bupati di masa mendatang. Pada sisi lain, akibat-akibat buruk yang dikhawatirkan itu pun dapat dijadikan titik dasar regulasi atau pembentukan aturan main atau peraturan perundangan yang lebih maju di masa depan.

Terlepas dari perdebatan dua kutub di atas, sesungguhnya ada pertanyaan yang lebih besar dalam setiap pergelaran pemilihan langsung calon presiden, gubernur, atau bupati. Pertanyaan tersebut terkait pula dengan persoalan pengetahuan dan pendidikan politik atau tentang partisipasi politik rakyat. 
Inilah pertanyaan itu: "Dari manakah sebenarnya demokrasi dimulai dalam konteks pemilihan langsung kepala negara atau kepala daerah?" Kasus-kasus yang berkaitan dengan pemilihan gubernur dan bupati di bawah ini akan menjadi jawaban tidak langsung atas pertanyaan tersebut.

\section{Polemik Pemilihan Gubernur dan RUU Keistimewaan LiY}

Tulisan ini sesungguhnya tidak akan mengulang polemik yang berkaitan dengan kontroversi isi Rancangan Undang-undang Keistimewaan Daerah Istimewa Yogyakarta (RUUKDIY) selama seperempat akhir tahun 2002 hingga bulan-bulan awal 2003 lalu. Di sini, fokus pembahasan akan diperlebar ke sisi yang paling strategis yaitu soal pemilihan calon Gubernur DIY dan kinerja Dewan Perwakilan Rakyat Daerah (DPRD) Propinsi DIY. Namun demikian, titik pijak bahasan ini tetap berangkat dari masalah RUUK DIY yarg saat itu pembahasannya selalu ditunda-tunda akibat kinerja Panitia Khusus (Pansus) RUUK DIY yang sangat buruk seperti tidak ada sosialisasi, dialog, dan transparansi yang terarah secara baik kepada publik.

Ada tiga isu besaryang berkaitan dengan keistimewaan DIY yaitu, 1) soal posisi Kraton (Kasultanan dan Pakualaman) dalam konstelasi politik modem; 2) soal pertanahan yang terkait dengan Sultan atau Pakualaman Ground; dan 3) soal keistimewaan DIY dalam konteks desentralisasi atau otonomi daerah. ${ }^{1}$ Dalam konteks ini, kajian akan kita fokuskan pada struktur politik dan mekanisme berdemokrasi di DIY (poin 1), khususnya menyangkut hubungan antara Dewan Perwakilan Rakyat Daerah (DPRD) Propinsi DIY dan Pemerintah Propinsi DIY, khususnya soal pemilihan calon gubernur DIY.
Sebelum masuk ke fokus masalah di atas, layak pula dibahas lebih dulu tentang makna keistimewaan. Keistimewaan yang berakar dari kata "istimewa" itu merupakan kata sifat. Ketika kita berbicara soal sifat, maka kita memerlukan objek atau bentuk atau wujud yang bisa dilekati oleh sifat itu. Dari sekian banyak polemik dan analisis menunjukkan bahwa sifat istimewa DIY yang dirangkum dalam RUUK DIY itu * tidaklah istimewa karena juga dimiliki oleh daerah-daerah lain di indonesia.

Kalau demikian adanya, maka di manakah letak keistimewaan DIY yang sesungguhnya itu? Keistimewaan itu nampaknya lebih relevan bila dilekatkan pada Sultan sendiri dalam fungsinya sebagai Raja Yogyakarta. Argumen ini terkait dengan asalusul wilayah Propinsi DIY yang semula merupakan wilayah kerajaan Mataram dan secara fisik maupun kultural masih ada akar serta pendukungnya. ${ }^{2}$ Pada konteks ini, posisi Sultan sama saja dengan_daerahdaerah lain di Indonesia yang masih memiliki pemimpin atau kepala adat serta perangkat hukum adat. Jadi, titik inilah yang tidak pernah dipikirkan dan dikaji secara serius. Dengan kata lain, bila rakyat DIY pernah memiliki hukum adat atau aturan-aturan adat baik yang tertulis di dalam kitab-kitab adat maupun yang telah mati, maka hal itu bisa dirujuk dan direvitalisasi ke dalam hukum formal di tingkat DIY. Bila tidak ada, maka formulasinya dapat diambil dari kehendak dan keinginan rakyat DIY sendiri sehingga tidak melulu menggunakan argumen

\footnotetext{
1 Abdur Rozaki dan Titok Hariyanto (Ed.), Membongkar Mitos Keistimewaan Yogyakarta, Yogyakarta: IRE Press, 2003, halaman 10.

${ }^{2}$ Lihat A. Im'an Sukri, dkk., Masa Depan Yogyakarta dalam Bingkai Keistimewaan, Yogyakarta: Unit Penerbitan Parwi Foundation, 2002, halaman 10-12.
} 
berdasarkan dokumen hukum atau peraturan perundangan pada masa lampau yang secara historis memang faktual, tetapi secara politis justru kadaluwarsa. Mekanisme polling atau referendum dapat digunakan di sini untuk menakar kehendak dan keinginan rakyat DIY itu sekaligus sebagai ajang pelajaran berharga dalam cara berpolitik yang partisipatif dan rasional.

Selain itu, walaupun polemik tentang keistimewaan DIY dan posisi Kraton (saat itu) bersumbu pada isu demokratisasi, tetapi harus menghindari lebih dulu perdebatan kamusistik (tata bahasa) tentang makna "tradisional" dan "modern". Asumsinya, halhal yang berkait dengan kearifan-tradisional juga bisa menjadi kearifan-demokratis, sedangkan hal-hal yang berkaitan dengan sikap hidup modern bisa saja terjerembab pada antidemokrasi atau kekerasan. Lebih dari itu, konstitusi Negara Kesatuan Republik Indonesia dan Undang-undang Nomor 22 Tahun 1999 cukup memberikan payung pada hal-hal yang berhubungan dengan asal-asul, tradisi, dan kearifantradisional yang bisa dipakai sebagai model kepemimpinan masyarakat lokal.

Bila disepakati bahwa keistimewaan DIY terletak pada Sultan sebagai Raja dan RUUK DIY dibuat dalam rangka menjaga posisi Sultan sebagai Raja agar tidak tenggelam oleh mekanisme tata pemerintahan Negara Kesatuan Republik Indonesia, maka perdebatan sudah dapat diubah ke arah otonomi khusus. Secara otomatis pembahasan RUUKDIY tidak lagi diperlukan sebab yang diperlukan ialah merancang Undang-undang Khusus DIY yang berisi tentang sifat, prinsip, dan mekanisme berdemokrasi dalam propinsi kerajaan DIY.

Lebih dalam lagi, perdebatan dapat diarahkan pada bagaimana membangun DIY sebagai daerah kerajaan dengan undang- undang khusus dan dengan mekanisme serta budaya politik modern. Salah satu polemik RUUK DIY saat itu ialah tentang mekanisme memilih dan dipilih menjadi Gubernur DIY serta hubungannya dengan hak Sultan sebagai Raja Kesultanan Mataram. Dalam salah satu pasal RUUKDIY dinyatakan bahwa Sultan Ngayogyakarta otomatis menjadi Gubernur DIY, sedangkan Pakualam otomatis menjadi Viakil Gubernur DIY. Lantaran itu, Dewan Perwakilan Rakyat Daerah (DPRD) Propinsi DIY dan seluruh partai politik yang ada di dalamnya menjadi tidak berfungsi dalam konstelasi pemilihan umum calon gubernur di DIY. Pada satu sisi, rakyat DIY akan kehilangan kesempatan ambil bagian dalam perpolitikan di DIY, dan pada sisi lain para politisi DIY akan kehilangan kesempatan menjadi pemimpin pemerintahan di tingkat propinsi. Apakah ini merupakan langkah mundur atau langkah maju? Tidak ada yang bisa menjawab pertanyaan itu bila di dalam politik kita memakai adagium "tidak ada pertemanan yang abadi dalam politik kecuali kepentingan". Akhirnya, polemik calon Gubernur DIY pun berkisar diantara dua opsi, yaitu dengan cara pemilihan ataukah dengan cara penetapan, dan pilihan dari kedua cara itu hanya tetap terjadi di dalam gedung Dewan Perwakilan Rakyat Daerah (DPRD) Propinsi DIY alias bukan pemilihan umum langsung yang melibatkan seluruh rakyat DIY.

Bila mau, berdasarkan konsep dan mekanisme kerajaan yang demokratis, persaingan politik atau perebutan kekuasaan tidak terjadi pada keinginan untuk menjadi Raja, melainkan terjadi pada perebutan posisi sebagai pelaksana harian pemerintahan kerajaan. Dalam kata mudahnya, pelaksana harian pemerintahan kerajaan itu dapat disemacamkan dengan Perdana Menteri sebagaimana pada Negara Kerajaan yang berkonstitusi modern. Dalam konteks 
DIY, tentu saja hal itu tidak dapat dimaknai sebagai negara dalam negara, kecuali negara Indonesia akan diubah menjadi . berbentuk negara federal.

Pikiran ini diajukan dalam rangka memberdayakan atau memberikan peluang kepada para politisi dari seluruh partai politik agar memiliki keberanian untuk menjadi Gubernur atau Kepala Pemerintahan Propinsi DIY. Selama ini, para politisi itu hanya dapat bercita-cita menjadi penguasa di level yang paling rendah seperti menjadi bawahan Gubernur Propinsi DIY atau cukup menjadi Kepala Pemerintahan Kabupaten/
Kota. Di luar itu, paling-paling para politisi partai politik di DIY hanya dapat berharap menjadi anggota legislatif di tingkat propinsi dan kabupaten atau kota. Hal ini terjadi karena setiap politisi mengidap perilaku politik sungkan, ewuh pakewuh pada Sultan. Karena hal itu pula, para politisi yang menjadi anggota Pansus RUUK DIY tidak bisa menghapus salah satu pasal dalam RUUK DIY yang mengotomatıskan Sultan menjadi gubernur dan Pakualam menjadi wakil gubernur itu.

Tabel yang disusun Sutoro Eko ${ }^{3} \mathrm{di}$ bawah ini dapat lebih menjelaskan

\section{Tabel 1}

\section{Haluan dan Wacana tentang Keistimewaan Yogyakarta}

\begin{tabular}{|c|c|c|}
\hline Pandangan & Konservatif & Transformatif \\
\hline Posisi kraton. & $\begin{array}{l}\text { Kraton dan propinsi } \\
\text { diintegrasikan. }\end{array}$ & $\begin{array}{l}\text { Kraton dan propinsi harus dipisah } \\
\text { secara tegas. Kraton adalah simbol } \\
\text { budaya Yogyakarta. }\end{array}$ \\
\hline Kepala Daerah. & $\begin{array}{l}\text { Sultan dan Pakualam otomatis } \\
\text { menjadi Gubernur dan Wakil } \\
\text { Gubernur. }\end{array}$ & $\begin{array}{l}\text { Kepala Daerah tidak otomatis dipegang } \\
\text { oleh Sultan dan Pakualam, tetapi haruis } \\
\text { dipilih secara demokratis melalui } \\
\text { kompetisi publik. }\end{array}$ \\
\hline Kepemimpinan. & $\begin{array}{l}\text { Kharismatik dan penuh } \\
\text { kebajikan (benevolent). }\end{array}$ & Transformatif. \\
\hline Pertanahan. & $\begin{array}{l}\text { Tanah dikuasai kraton dan } \\
\text { propinsi. }\end{array}$ & $\begin{array}{l}\text { Harus ada land reform terhadap sultan } \\
\text { ground untuk kepentingan rakyat. }\end{array}$ \\
\hline Otonomi Daerah. & Berbasis pada propinsi. & $\begin{array}{l}\text { Berbasis pada masyarakat } \\
\text { (Kabupaten/Kota). }\end{array}$ \\
\hline Basis kekuasaan. & Feodalisme. & Demokrasi. \\
\hline Paradigma politik. & Klientelisme. & Kewargaan (citizenship). \\
\hline Posisi rakyat. & $\begin{array}{l}\text { Rakyat sebagai kowula yang } \\
\text { harus patuh pada Kraton. }\end{array}$ & $\begin{array}{l}\text { Rakyat sebagai warga harus mempunyai } \\
\text { kesadaran kritis. }\end{array}$ \\
\hline $\begin{array}{l}\text { Justifikasi } \\
\text { pandangan. }\end{array}$ & $\begin{array}{l}\text { Konteks budaya yang khas, } \\
\text { sejarah masa lalu, dan legal- } \\
\text { formal (undang-undang). }\end{array}$ & $\begin{array}{l}\text { Konteks kekinian: demokratisasi, } \\
\text { desentralisasi, pemberdayaan rakyat, } \\
\text { dan kompleksitas Yogyakarta. }\end{array}$ \\
\hline Visi & $\begin{array}{l}\text { Mempertahankan status formal } \\
\text { keistimewaan yang sudah ada. }\end{array}$ & $\begin{array}{l}\text { Mendorong perubahan keistimewaan ke } \\
\text { arah yang lebih bermakna dan sesuai } \\
\text { dengan konteks kekinian tanpa harus } \\
\text { menggusur keberadaan Kraton. }\end{array}$ \\
\hline
\end{tabular}

${ }^{3}$ Sutoro Eko, "Membuat Keistimewaan Lebih Istimewa," dalam Abdur Rozaki dan Titok Hariyanto (Ed.), Membongkar Mitos Keistimewaan Yogyakarta, Yogyakarta: IRE Press, 2003, halaman xoxiii. 


\section{Topik: Pemilu dan Pemilihan Presiden \& Wakil Presiden}

perbedaan substansi keistimewaan DIY antara yang diinginkan oleh kelompok prodemokrasi atau kelompok transformatif dan yang diinginkan oleh kelompok konservatif.

Tampaknya, tabel ini merupakan perbandingan ekstrem yang disarikan Sutoro Eko dari isi RUUK DIY versus ide-ide, usul, dan saran dari para kritikus RUUK DIY. Berangkat dari gambaran ekstrem kedua kutub dalam tabel ini, maka tidak tertutup kemungkinan untuk mencari resolusi atau jalan tengah seperti gagasan menjadikan DIY sebagai daerah khusus kerajaan-demokratis yang tetap berada dalam Negara Kesatuan Republik Indonesia.

Pada ujungnya, ada tiga kenyataan yang dapat dipetik dan dijadikan pelajaran dari polemik atau pro dan kontra masyarakat DIY terhadap RUUKDIY di atas:

Pertama, menunjukkan buramnya wajah lembaga legislatif (DPRD) DIY. Selain tampak kuwalahan menghadapi tekanan masyarakat yang menolak RUUK DIY karena tidak memiliki konsep alternatif yang baik, juga tampak lemah secara institusi akibat belitan kasus korupsi yang melibatkan sejumlah anggotanya. Padahal, lembaga legislatif merupakan salah satu pilar pemajuan demokrasi yang menyimbolkan kuat atau lemahnya partisipasi politik rakyat. Dalam konteks RUUK DIY, lembaga legislatif masih belum bergeser dari stigma lamanya yaitu sebagai lembaga stempel atau lembaga yang lebih banyak melayani dirinya sendiri. Contoh konkretnya tercemin pada buruknya kinerja Pansus RUUK DIY dan penyalahgunaan wewenang dalam kasus korupsi dana pembangunan gedung Jogjakarta Expo Center (JEC), atau pada kasus penggelapan dana asuransi. Jadi, lembaga legislatif (DPRD) DIY saat ini telah berubah menjadi lembaga dari, oleh, dan untuk anggotanya sendiri!
Kedua, menunjukkan kuatnya posisi tawar lembaga eksekutif (Pemerintah Propinsi DIY). Apalagi, perdebatan RUUK DIY di Pansus RUUK DIY saat itu tidak dilakukan pada dataran "menolak" atau "menerima", melainkan merevisi, mengurangi atau menambahi. Dalam kondisi seperti ini, Sultan yang saat itu sekaligus berposisi sebagai Gubernur DIY tidak perlu khawatir RUUK. DIY itu ditolak atau dibatalkan. Oleh karena itu, sikap diam Sultan merupakan pilihan yang tepat secara politis, walaupun kerasnya berbagai tanggapan dan kuatnya kecurigaan dari berbagai pihak soal adanya money politics oleh pihak Kraton.

Ketiga, banyaknya lubang jala yang mematikan dari kaum akademisi yang menjadi legal drafter sebuah rancangan undang-undang seperti RUUK DIY. Sesungguhnya, pihak eksekutif maupun legislatif memang sangat memerlukan sumbangan pemikiran dari kaum akademisi. Apalagi, persoalan yang harus dipikirkan itu berkaitan dengan pembangunan politik dan ekonomi daerah yang memerlukan legitimasi hukum. Akan tetapi, kaum akademisi kadang sering tergelincir menjadi aktor pendukung atau memperkuat rezim yang jelas-jelas tidak demokratis. Dalam arti lain, produk pemikiran dari kaum akademisi itu tidak berpihak pada rakyat, melainkan melayani dan mengusung kepentingan sepihak para elit politik yang ingin tetap berkuasa.

Berdasarkan uraian dari tiga kenyataan di atas, maka terlihat bahwa hubungan antara lembaga legislatif (DPRD) DIY dan lembaga eksekutif (Pemerintah Propinsi DIY) tidak berada dalam keseimbangan. Dalam kasus RUUK DIY, dapat dikatakan bahwa lembaga legislatif (DPRD) DIY berada di posisi yang sangat tidak aspiratif/ 
akomodatif dibanding lembaga eksekutif (Pemerintah Propinsi DIY). Kadangkala, lembaga legislatif (DPRD) DIY itu terbentur oleh kerumitan prosedur, tata-tertib, dan logika "asal jadi". Apalagi, khususnya di DIY, lembaga legislatif (DPRD) DIY mengidap penyakit "politik sungkan" kepada Sultan.

Semua pihak telah menyadari bahwa RUUK DIY tidak mungkin lagi dibatalkan kecuali hanya direvisi pada bagian-bagian tertentu. Perdebatan tentang prinsip dan fakta keistimewaan DIY pun akhirnya mengalami titik jenuh. Sebenarnya hal ini sangat berbahaya bagi perkembangan demokrasi di DIY karena akan mematikan partisipasi kritis masyarakat dalam bidang politik. Selain itu, juga akan kian memperbesar ketidakpercayaan masyarakat pada lembaga legislatif (DPRD) DIY yang seharusnya menjadi mediator dan penyambung isi pikiran masyarakat.

Akan tetapi, masih belum terlambat. Ada jalan dan langkah ke depan yang memerlukan tenaga, pemikiran, dan semangat baru. Ketika RUUK DIY telah resmi menjadi Undang-undang Keistimewaan DIY, maka untuk mengimplementasikannya masih memerlukan peraturan pelaksanaan di bawahnya. Dalam proses inilah partisipasi semua pihak dibutuhkan, terutama dalam rangka pemantauan dan advokasi (korban) kebijakan. Jadi, tindakan selanjutnya ialah "menghentikan perundingan dan menyerang lebih dulu pada bagian yang belum dipikirkan itu".

Hal yang lebih penting dan sangat mendesak dipikirkan ke depan ialah bagaimana menggagas pemilihan umum langsung bagi calon gubernur di DIY sehingga mejadi ajang pendidikan politik semesta dan paket awal bagi proses demokratisasi politik untuk level nasional. Secara politik, kejadian dalam pemilihan calon Gubernur DIY dalam kerangka keistimewaan DIY di atas sesungguhnya tidak memberikan efek demokratisasi sama sekali bagi rakyat karena hanya dipikirkan oleh segelintir elit akademisi dan hanya didiskusikan oleh sekelompok politisi di DPRD DIY.

\section{Konflik Elitis dalam Pemilihan Gubernur at:u Bupati}

Macetnya demokratisasi di daerah dalam pemilihan kepala daerah baik pemilihan gubernur atau bupati/wali kota disebabkan berbagai faktor. Faktor yang paling menonjol disebabkan oleh banyaknya kepala daerah yang masih terikat pada partai politiknya. Di sini, ada kewajiban balas budi dari kepala daearah itu kepada partai politiknya dalam bentuk usaha memperbanyak suara pemilih dalam setiap pemilihan umum. Afiliasi partai politik para kepala daerah inilah yang menjadi salah satu penghambat proses demokratisasi dan pemandul kekuatan partisipatif rakyat secara langsung.

Dengan demikian, bila diteropong berdasarkan konsep civil society (masyarakat kewargaan), ${ }^{4}$ maka problem afiliasi kepala daerah baik gubernur atau bupati/wali kota kepada partai politik tertentu itu hanya akan menghasilkan konflik elitis

${ }^{4}$ Menurut M. Ryaas Rasyid, civil society atau masyarakat kewargaan pada hakikatnya merupakan suatu konsep tentang keberadaan masyarakat yang mandiri dan dalam batasbatas tertentu mampu memajukan dirinya sendiri serta cenderung membatasi intervensi negara ke dalam realitas yang telah diciptakan sebagai ruang kegiatannya. Lihat $M$. Ryaas Rasyid, "Perkembangan Pemikiran tentang Masyarakat Kewargaan (Tinjauan Teoritik), dalam Jurnal IImu Politik No. 17, Jakarta: Asosiasi IImu Politik Indonesia (AIPI), Lembaga limu Pengetahuan Indonesia (LIPI), dan Gramedia Pustaka Utama, 1997, him 3. 
Topik: Pemilu dan Pemilihan Presiden \& Wakil Presiden

yang tidak mencerdaskan rakyat banyak. Dalam tabel yang disusun Litbang Kompas $(2003)^{5}$ di bawah ini dapat kita lihat jumlah atau persentase gubernur dan bupati/wali kota yang memiliki afiliasi pada partai politik tersebut: tentu ada aktor yang tidak terlihat, tetapi super kuat, yaitu Presiden R.I. sendiri. Dua tabel di bawah ini akan menggambarkan suasana konflik elitis dalam pemilihan gubernur atau bupati di beberapa daerah pada masa Orde Baru. ${ }^{6}$

Tabel 2

Peta Afiliasi Politik Kepala Daerah

\begin{tabular}{|l|l|c|c|c|c|}
\hline No & \multicolumn{1}{|c|}{ Afiliasi } & Gubernur & $\begin{array}{c}\text { Persentase } \\
\cdot\end{array}$ & $\begin{array}{c}\text { Bupati/Wali } \\
\text { Kota }\end{array}$ & Persentase \\
\hline 1 & Partai Golkar & 14 & 43,8 & 152 & 36,6 \\
\hline 2 & Birokrat/PNS & 3 & 9,4 & 130 & 31,3 \\
\hline 3 & PDI-Perjuangan & 2 & 6,3 & 68 & 16,4 \\
\hline 4 & Partai Kebangkitan Bangsa & - & - & 16 & 3,9 \\
\hline 5 & Partai Persatuan Pembangunan & 3 & 9,4 & 12 & 2,9 \\
\hline 6 & TNI/Polri/Purnawirawan & 6 & 18,8 & 11 & 2,7 \\
\hline 7 & Partai Amanat Nasional & 1 & 3,1 & 5 & 1,2 \\
\hline 8 & Partai Demokrasi Kasih Bangsa & - & - & 1 & 0,2 \\
\hline 9 & Partai Indonesia Baru & - & - & 1 & 0,2 \\
\hline 10 & Partai Bulan Bintang & - & - & 1 & 0,2 \\
\hline 11 & $\begin{array}{l}\text { Partai Bhinneka Tunggal Ika } \\
\text { Indonesia }\end{array}$ & - & - & 1 & 0,2 \\
\hline 12 & Tidak ada data & 32 & 100 & 415 & 100 \\
\hline & Total & & & 17 & 4,1 \\
\hline
\end{tabular}

Konflik elitis dalam pemilihan gubernur atau bupati sesungguhnya sudah sering terjadi pada masa Orde Baru. Bukan cerita baru pula bila konflik elit para birokrat atau politisi tersebut lebih bernuansa adu kepentingan pribadi, kelompok atau golongan, bukan atas kepentingan rakyat banyak. Selain itu, konflik elitis tersebut pun menjadi gambaran yang transparan mengenai kuatnya intervensi pemerintah pusat yang diwakili oleh institusi Markas Besar ABRl (kini, TNl), DPP Golkar, atau Menteri Dalam Negeri. Di balik semua itu,
${ }^{5}$ Kompas, Jum'at, 16 Januari 2004, halaman 8.

6 Kedua tabel tersebut disusun oleh penulis dari tulisan Riswandha Imawan, "Rekrutmen Kepemimpinan di Daerah: Antara Keinginan dan Kebutuhan Masyarakat," dalam Jurnal IImu Politik No. 17, Jakarta: Asosiasi ilmu Politik Indonesia (AIPI), Lembaga Ilmu Pengetahuan Indonesia (LIPI), dan P.T. Gramedia Pustaka Utama, 1997, halaman 36-39. 
Efek Demokrasi Dalam Pemilihan Langsung Calon Gubernur..., Mulyadi J. Amalik

\section{Tabel 3}

\section{Konflik Elitis dalam Pemilihan Gubernur}

\begin{tabular}{|c|c|c|c|}
\hline Kasus & Keterangan Calon & - Kelompok Terlibat & Faktor Ketegangan/Konflik \\
\hline $\begin{array}{l}\text { Pemilihan } \\
\text { Gubernur Riau } \\
\text { di DPRD } \\
\text { Propinsi Riau, } \\
\text { September } \\
1985 .\end{array}$ & $\begin{array}{l}\text { Mayjend Imam } \\
\text { Munandar sebagai . } \\
\text { calon jadi } \\
\text { dikalahkan oleh } \\
\text { calon } \\
\text { pendampingnya, H. } \\
\text { Ismail Suko: }\end{array}$ & $\begin{array}{l}\text { - Mabes ABRI (TNI). } \\
\text { - DPP Golkar. } \\
\text { - DPRD I Riau. } \\
\text { - Masyarakat dan tokoh } \\
\text { adat Riau. }\end{array}$ & $\begin{array}{l}\text { - Mabes ABRI (TNI) } \\
\text { menggunakan "politik } \\
\text { komando" yang } \\
\text { memutuskan Imam } \\
\text { Munandar harus terpilih. . } \\
\text { - DPP Golkar tidak dapat } \\
\text { berbuat apa-apa. } \\
\text { - Masyarakat dan tokoh adat } \\
\text { Riau menolak Imam } \\
\text { Munandar karena gagal } \\
\text { membangun Riau dan tidak } \\
\text { cocok dengan norma- } \\
\text { noma masyarakat Melayu. }\end{array}$ \\
\hline $\begin{array}{l}\text { Pemilihan } \\
\text { Gubernur } \\
\text { Aceh di DPRD } \\
\text { Propinsi Aceh, } \\
\text { Mei 1993. }\end{array}$ & $\begin{array}{l}\text { Ir. Usman Hasan } \\
\text { sebagai calon DPP } \\
\text { Golkar dikalahkan } \\
\text { calon daerah, Prof. } \\
\text { Dr. Syamsudin } \\
\text { Mahmud dari } \\
\text { Universitas Syah } \\
\text { Kuala, Aceh. } \\
\end{array}$ & $\begin{array}{l}\text { - DPP Golkar. } \\
\text { - DPRD Propinsi Aceh. } \\
\text { - Masyarakat dan tokoh- } \\
\text { tokoh lokal Aceh. }\end{array}$ & $\begin{array}{l}\text { DPP Golkar berkeras } \\
\text { menerapkan "politik cangkok" } \\
\text { (dropping political). } \\
\text { sementara masyarakat dan } \\
\text { tokoh lokal Aceh } \\
\text { menginginkan putra daerah } \\
\text { sebagai Gubernur. }\end{array}$ \\
\hline $\begin{array}{l}\text { Pemilihan } \\
\text { Gubernur : } \\
\text { Kalimantan } \\
\text { Tengah di } \\
\text { DPRD } \\
\text { Propinsi } \\
\text { Kalteng, } \\
\text { Desember } \\
1993 .\end{array}$ & $\begin{array}{l}\text { Drs. Karna } \\
\text { Suwanda sebagai } \\
\text { calon jadi dari } \\
\text { Pemerintah Pusat } \\
\text { ditolak masyarakat } \\
\text { Kalteng yang } \\
\text { memliki calon dari } \\
\text { daerahnya sendiri, } \\
\text { DJ. Nihin. }\end{array}$ & $\begin{array}{l}\text { - Pemerintah Pusat } \\
\text { (Departemen Dalam } \\
\text { Negeri). } \\
\text { - FKP DPRD Propinsi } \\
\text { Kalteng. }\end{array}$ & $\begin{array}{l}\text { - Drs. Karna Suwanda } \\
\text { sebagai calon jadi dari } \\
\text { Pemerintah Pusat } \\
\text { dianggap tidak tahu soal } \\
\text { adat-istiadat masyarakat } \\
\text { Kalteng. } \\
\text { - Usia Drs. Karna Suwanda } \\
\text { di atas } 60 \text { tahun, dan lebih } \\
\text { tua dari Gubernur Kalteng } \\
\text { yang akan diganti. } \\
\text { - Depdagri memunculkan } \\
\text { calon baru, Drs. Warsito } \\
\text { Rasman, M.A., yang berarti } \\
\text { menghadang DJ. Nihin } \\
\text { sebagai calon masyarakat } \\
\text { Kalteng. }\end{array}$ \\
\hline
\end{tabular}




\section{Tabel 4}

\section{Konflik Elitis dalam Pemilihan Bupati}

\begin{tabular}{|c|c|c|c|}
\hline Kasus & Keterangan Calon & Kelompok Terlibat & Faktor Ketegangan/Konflik \\
\hline $\begin{array}{l}\text { Pemilihan } \\
\text { Bupati Kutai di } \\
\text { DPRD } \\
\text { Kabupaten } \\
\text { Kutai, Maret } \\
1994 .\end{array}$ & $\begin{array}{l}\text { Drs. Sammy } \\
\text { Ridwan sebagai } \\
\text { calon jadi } \\
\text { dikalahkan calon } \\
\text { pendampingnya, } \\
\text { Drs. HAM } \\
\text { Sulaiman. }\end{array}$ & $\begin{array}{l}\text { - Menteri Dalam Negeri. } \\
\text { - Dirjen PUOD. } \\
\text { - FKP DPRD Kabupaten } \\
\text { Kutai. } \\
\text {. . . }\end{array}$ & $\begin{array}{l}\text { - Mendagi menganggap } \\
\text { pemilhan bupati itu tidak } \\
\text { sah karena tidak } \\
\text { memenuhi kuorum. } \\
\text { - Anggota FKP DPRD } \\
\text { Kabupaten Kutai } \\
\text { memboikot pemilihan } \\
\text { bupati agar Drs. Sammy } \\
\text { Ridwan tidak terpilih. } \\
\text { - Ketika pemilihan bupati } \\
\text { diulang, tetap saja Drs. } \\
\text { HAM Sulaiman yang } \\
\text { terpilih. } \\
\end{array}$ \\
\hline $\begin{array}{l}\text { Pemilihan } \\
\text { Bupati Ngada, } \\
\text { Flores Timur, } \\
\text { NTT, Maret } \\
\text { 1994. }\end{array}$ & $\begin{array}{l}\text { Pencalonan Drs. } \\
\text { Joachim Reo } \\
\text { (Bupati lama) } \\
\text { ditolak masyarakat } \\
\text { diantara } 2 \text { calon } \\
\text { lainnya, yaitu Drs. } \\
\text { Johanes Aoh dan } \\
\text { Drs. Timoteos } \\
\text { Messakh } \\
\text { Hermanus. } \\
\end{array}$ & $\begin{array}{l}\text { - Masyarakat Ngada, } \\
\text { Flores Timur, NTT. } \\
\text { - } \text { DPD PDI Kabupaten } \\
\text { Ngada. }\end{array}$ & $\begin{array}{l}\text { - Masyarakat menganggap } \\
\text { Joachim Reo menyogok } \\
\text { Ketua Cabang DPD PDI } \\
\text { Ngada agar lolos dalam } \\
\text { pemilihan bupati. } \\
\text { - Mentalitas calon pemimpin } \\
\text { lokal yang bertentangan } \\
\text { dengan prinsip civil } \\
\text { society, yaitu kejujuran } \\
\text { dan kesederhanaan. } \\
\end{array}$ \\
\hline $\begin{array}{l}\text { Pemilihan } \\
\text { Bupati Flotim, } \\
\text { Flores Timur, } \\
\text { NTT, Maret } \\
1994 .\end{array}$ & $\begin{array}{l}\text { Masyarakat } \\
\text { menginginkan Drs. } \\
\text { Andreas Duli } \\
\text { Manuk terpilih } \\
\text { sebagai Bupati } \\
\text { Flotim, tetapi malah } \\
\text { terpilih Drs. } \\
\text { Hendrikus Henky } \\
\text { Mukim, S.H. }\end{array}$ & $\begin{array}{ll} & \text { FKP DPRD } \\
\text { Kabupten Flotim, } \\
\text { NTT. } \\
\text { - Ketua DPD Golkar } \\
\text { Propinsi NTT. }\end{array}$ & $\begin{array}{l}\text { - Anggota FKP DPRD } \\
\text { Kabupten Flotim menuntut } \\
\text { Drs. Hendrikus Henky } \\
\text { Mukim, S.H., mundur } \\
\text { sebagai Bupati terpilih. } \\
\text { - Ketua DPD Golkar Propinsi } \\
\text { NTT, JN Manafe dianggap } \\
\text { sebagai dalang terpilihnya } \\
\text { Drs. Hendrikus, dan } \\
\text { otomatis ia ingkar janji } \\
\text { dalam memperjuangkan } \\
\text { Drs. Andreas (Ketua DPD } \\
\text { Golkar Kabupaten Flotim, } \\
\text { NTT. }\end{array}$ \\
\hline
\end{tabular}


Dari dua tabel di atas terlihat bahwa konflik-konflik dalam pemilihan kepala daerah baik gubernur maupun bupati itu terjadi di lingkaran elit birokrat atau elit politik daerah/lokal versus elit birokrat atau elit politik pusat. Dengan demikian, kita tidak melihat keterlibatan rakyat secara langsung dan meluas dalam ketegangan pemilihan kepala daerah itu. Namun, dapat dicatat bahwe sudah ada gejala-gejala yang mengindikasikan keinginan elit politik daerah/lokal untuk menentukan nasib daerahnya sendiri yang terlepas sama sekali dari intervensi pemerintah pusat.

Oleh karena itu, gejala-gejala ini dapat dijadikan sebagai titik dasar dalam perubahan model pemilihan kepala daerah yang selama ini berkutat diantara kalangan DPRD saja, menjadi pemilihan umum langsung yang melibatkan seluruh rakyat $\mathrm{di}$ daerah yang bersangkutan.

\section{Efek Demokratisasi dalam Pemilihan Langsung}

Selain money politics dan politik konflik (adu domba), masalah yang juga sering mengganggu proses demokratisasi di Indonesia ialah personifikasi kekuasaan. Personifikasi atau personalisasi kekuasaan itu telah ada dan terjadi pada masa pemerintahan Orde Lama, Orde Baru, dan masih bersisa kuat pada masa Orde Reformasi saat ini. Di Jawa Tengah saja, misalnya, terdapat sedikitnya lima bupati yang menyalahgunakan wewenangnya untuk kepentingan partai politik tertentu. Kelima orang bupati itu memang masih berstatus sebagai pengurus dalam partai politik itu. ${ }^{7}$ Hal ini bisa terjadi karena dampak personalisasi atau personifikasi kekuasaan tersebut.

Bila dirunut dalam Undang-undang Pemilihan Umum Nomor 12 Tahun 2003, memang ada ketentuan yang membolehkan pejabat negara yang berasal dari partai politik, mulai dari presiden, wakil presiden, menteri, gubernur, wakil gubernur, bupati, wakil bupati, wali kota, wakil wali kota, untuk berkampanye. Namun, mereka tetap tidak boleh menggunakan fasilitas negara yang terkait dengan jabatannya itu. ${ }^{8}$ Bila hal ini terjadi, maka sudah dapat dikategorikan bahwa para pejabat nega -iyang berasal dari partai politik tersebut telah melakukan korupsi.

Untuk itu, ada beberapa efek demokratisasi yang dapat dicatat dalam pemilihan secara langsung terhadap kepala daerah baik gubernur atau bupati. Efek tersebut tentu saja terkait dengan prinsip civil society yang selama ini banyak terhambat oleh model pemerintahan Indonesia yang sentralistik dan otoriter serta model tradisional yang cenderung mempersonifikasi atau mempersonalisasi kekuasaan.

Pertama, pemilihan langsung kepala daerah baik gubernur atau bupati akan memotong intervensi pemerintah pusat dan berarti dapat menghadang kemungkinan sentralisasi kekuasaan.

Kedua, pemilihan langsung kepala daerah baik gubernur atau bupati akan memberikan peluang bagi politisi daerah/ lokal banyak belajar menjadi pemimpin yang mengakar sebelum memasuki arena politik nasional dan internasional.

Ketiga, pemilihan langsung kepala daerah baik gubernur atau bupati memang tidak menjamin hilangnya money politics dan personifikasi kekuasaan, tetapi dapat memperpendek arus pengawasan dan kontrol oleh masyarakat.

\footnotetext{
${ }^{7}$ Kompas, 16 Januari 2004, Op. Cit.

${ }^{3}$ Ibid.
} 
Topik: Pemilu dan Pemilihan Presiden \& Wakil Presiden

Keempat, pemilihan langsung kepala daerah baik gubernur atau bupati akan memungkinkan rakyat terlibat secara langsung dalam menilai dan menentukan pemimpin daerahnya sehingga betul-betul representatif.

Kelima, pemilihan langsung kepala daerah baik gubernur atau bupati akan memfungsikan DPRD sebagai pihak netral sekaligus sebagai penyelenggara, pengawas, dan pemantau setiap calon gubernur atau bupati yang ikut pemilihan.

Keenam, pemilihan langsung kepala daerah baik gubernur atau bupati akan memotong elitisme politik selama ini sehingga betul-betul menjadi pesta rakyat.

\section{Daftar Pustaka}

Abdur Rozaki dan Titok Hariyanto (Ed.),2003, Membongkar Mitos Keistimewaan Yogyakarta, Yogyakarta: IRE Press.

A. Im'an Sukri, dkk., 2002, Masa Depan Yogyakarta dalam Bingkai Keistimewaan, Yogyakarta: Unit Penerbitan Parwi Foundation.
Sutoro Eko, "Membuat Keistimewaan Lebih Istimewa," dalam Abdur Rozaki dan Titok Hariyanto (Ed.), 2003, Membongkar Mitos Keistimewaan Yogyakarta, Yogyakarta: IRE Press.

M. Ryaas Rasyid, "Perkembangan Pemikiran tentang Masyarakat Kewargaan (Tinjauan Teoritik)," dalam Jurnal IImu Polrik No. 17, Jakarta: Asosiasi llmu Politik Indonesia (AIPI), Lembaga llmu Pengetahuan Indonesia (LIPI), dan P.T. Gramedia Pustaka Utama, 1997.

Riswandha Imawan, "Rekrutmen Kepemimpinan di Daerah: Antara Keinginan dan Kebutuhan Masyarakat," dalam Jurnal IImu Politik No. 17, Jakarta: Asosiasi ilmu Politik indonesia (AIPI), Lembaga IImu Pengetahuan Indonesia (LIPI), dan P.T. Gramedia Pustaka Utama, 1997

Kompas, Jum'at, 16 Januari 2004. 